\title{
Identifying Consumer Lifestyles through Their Energy Impacts: Transforming Social Science Data into Policy-Relevant Group-Level Knowledge
}

\author{
Stephan Schwarzinger ${ }^{1}$, David Neil Bird ${ }^{2, *} *$ and Tomas Moe Skjølsvold ${ }^{3}$ \\ 1 Department of Sociology, University of Graz (until 05/2019: Joanneum Research Forschungsgesellschaft \\ $\mathrm{mbH}$ ), Universitätsstraße 15/G4, 8010 Graz, Austria; stephan.schwarzinger@uni-graz.at \\ 2 Centre for Climate, Energy and Society, Joanneum Research Forschungsgesellschaft mbH, \\ Leonhardstraße 59, 8010 Graz, Austria \\ 3 Department of Interdisciplinary Studies of Culture, Norwegian University of Science and \\ Technology (NTNU), Edvard Bulls veg 1, 7491 Trondheim, Norway; tomas.skjolsvold@ntnu.no \\ * Correspondence: neil.bird@joanneum.at; Tel.: +43-316-876-7633
}

Received: 28 September 2019; Accepted: 30 October 2019; Published: 4 November 2019

\begin{abstract}
The analytical framework presented herein is based on the identification of social groups with distinct patterns in their energy-relevant behaviour. This was achieved by clustering individuals according to their primary energy demands in six main areas of life. Due to the close relationship between energy-relevant behaviour and associated impacts, the suggested approach is considered better suited for the identification of groups with actual differences in their climate and energy-related behaviour than conventional approaches that cluster individuals based on their psychological or sociodemographic characteristics. Moreover, it is assumed that this focus on energy-relevant behaviour leads to a higher measuring equivalence in a country comparison or in a longitudinal setting. From an analytical point of view, the most significant benefit of the presented method over conventional lifestyle typologies is that all psychological, cultural and sociodemographic factors can be used as explanatory variables without resulting in circular reasoning. In terms of required data, the approach was designed around what could be collected by conventional survey methods. Variables such as energy use and emissions were calculated by the means of life cycle assessment (LCA) based on self-reported behaviour and equipment use.
\end{abstract}

Keywords: energy; lifestyle; behavior; lifecycle assessment; climate

\section{Introduction}

As a response to escalating environmental problems and climate change, we need society-wide transitions in a sustainable direction with respect to the production, distribution and consumption of energy and other goods [1,2]. Sustainability transition scholars have traditionally addressed these challenges by focusing primarily on systems of supply and technological innovation [3-7] rather than on consumption and everyday life [8-10]. In recent years, however, interest in the role of citizens or consumers as central agents in systemic change has increased in studies of sustainability transitions. This interest is often operationalised through a focus on the role of technology users in the transformation of socio-technical systems [11,12], e.g., as frontrunners involved in grassroots innovation [13]. Implicitly, this points towards the importance of understanding the role of people's lifestyles for changing broad societal trajectories. Indeed, the question of how to change lifestyles in a sustainable direction has "rapidly become a focus of environmental policy and popular commentary on environmental issues" [14]. However, to date, the lifestyle concept has, also due to a missing terminological agreement, not been systematically and unambiguously represented in discussions on 
energy and sustainability transitions [15]. Our prime goal in this paper was to bring lifestyles to the fore in transition discussions by supporting a behaviour- and impact-centred understanding and to present a widely applicable research-framework.

Pierre Bourdieu defined "Life-Style" as "a system of classified and classifying practices ( . . . )" [16]. Early research to identify lifestyle variables within patterns of consumer activities within realms as travel, work, home leisure activities and service use succeeded [17]. Yet, within the contemporary transitions literature, "lifestyle" is seldom defined specifically, and there are few discussions about which practices constitute a lifestyle. Instead, "lifestyle" tends to be articulated as an abstract and poorly defined concept, e.g., discussed as part of a broader "socio-cultural stock" [18]. Lifestyles have been discussed as being shaped by local contexts, such as cities [19] and buildings [20], and as being embedded in and dependent upon specific socio-technical systems [13].

Such perspectives are important because they provide clues about some of the specificities needed to design effective interventions and policies aiming to influence and change lifestyles in a more sustainable direction. Indeed, recent high profile modelling research has highlighted the importance of an increased focus on the energy systems demand side [21], and calls have recently been made to more explicitly make lifestyles the target of actual policies rather than just being considered a voluntary add-on to broader transition efforts [22]. We agree that addressing lifestyles is crucial, but in order to design political instruments that target lifestyles, we must also have a firm grip on how lifestyles are constructed. Our goal in this article was to advance this agenda by placing the lifestyle concept centre stage in a discussion about decarbonising society. We do this by proposing the concept of impact-based lifestyle research, which zooms in on specific characteristics of lived lives with respect to estimating energy consumption and $\mathrm{CO}_{2}$ emissions, and assessing the driving factors behind different patterns of energy-relevant behaviour across different areas of life. This will provide an "enhanced comprehension of comparative qualities of lifestyles" as has been called for in social scientific energy studies [23]. Hence, our contribution in this article is methodological by strengthening the rigour of energy lifestyle research, but also conceptual in the sense that it helps to advance insights into what energy lifestyles are.

\section{Beyond Existing Research on Energy Lifestyles}

Today, studies that explicitly address energy-related lifestyles are rare. Lutzenhiser and Gossard [24] pointed out that for a brief moment in the early 1990s, the concept of lifestyle dominated social scientific energy studies, but that it has declined in presence and terminological clarity since then [15]. Thereby, the spectrum of scientific debate on energy lifestyles covers, for example, historical transformations [25], energy cultures on a macro level [26], and the role of energy crises and major events such as catastrophes [27]. In the quantitatively oriented studies that do exist, a common approach is to assess lifestyles through national statistics, analysing them through "demographic variables which are only crude indicators of energy use" [23]. Such statistics typically rely on average per capita numbers and thus only hardly account for the variance in individual behaviour.

Furthermore, most studies of energy-relevant behaviour have a primary focus on single areas of life (see e.g., [28]). Hence, they lack sensitivity to the relationships between different aspects of the lived experience within targeted groups. For example, public discourse tends to emphasise that people in western societies eat too much meat and use too much fossil fuel for land and air transport to achieve ecological sustainability. Hence, one could assume that the western lifestyle [29], or even "the Austrian" or "the Swedish" lifestyles, are by definition unsustainable. Although there have also been quite sophisticated approaches to identifying consumer-lifestyle related opportunities for policy design on a more aggregated (i.e., national) level [30], they conceal the complexities of human behaviour and limit the opportunities of producing targeted policies that work. Each individual has a specific energy demand profile and climate impact which renders national average per capita numbers virtually useless for many questions in target group-oriented policy design. Interestingly, beyond studies of income and other forms of resource allocation, the societal distribution of energy-relevant practices and related climate effects remain relatively underexplored. Recent approaches to segmenting groups on the basis 
of their smart-meter-generated energy consumption profiles in the household promise better insight into group-specific differences in that part of the lifestyle that occurs at home [31]. In order to shed some light on methods of lifestyle segmentation and to go beyond the portion that takes place at home, a number of aspects that are considered essential for energy-specific lifestyle research are discussed. First, however, we define our understanding of "lifestyle" in the context of climate and energy.

One way of conceptualising a lifestyle is as a form of "self-identity[ ... ] informed and expressed by engagement in lifestyle practices" [32]. As the "energy lifestyle" of a person, we therefore highlight the activities that are part of the person's private sphere of influence and have an impact on this person's energy demand and climate impact. Thus, the energy demand of privately consumed products and services (including trips between home and work) are part of the analysis whenever the lifespan of the respective product can be estimated to a reasonable extent, so that the energy demand for its provision can be reduced over time or per usage unit. This is, for example, the case with the most forms of mobility, food, and consumer goods, but not for residential buildings. Furthermore, the focus on the private sphere of influence means that, for example, the distance travelled by car between home and work is attributed to the individual lifestyle, while kilometres travelled for professional purposes (e.g., as a sales representative or a bus driver) are not a question of the individual's "energy lifestyle".

In the following section, three main limitations in conventional methodological approaches to lifestyles are discussed. We also elaborate on how our approach addresses these limitations.

\subsection{Limitation I: Limited Specificity and Comparability of Group Identification}

A key aim of lifestyle research is to identify lifestyle groups with distinct behavioural patterns. Most existing studies used methods for group identification that abstract from certain indicator variables to energy-related behaviour in general. One major methodological strand identifies groups by clustering individuals on the basis of psychological variables (e.g., environmental attitudes, norms, values) or behavioural "proxy" variables (e.g., the use of LEDs instead of conventional light bulbs). However, such come with two major disadvantages.

First, the choice of proxy variables often rests with individual researchers and strongly depends on the understanding of the term "lifestyle". To date, no common understanding of "lifestyle" seems to have been established in environment related research, which makes it difficult to answer the question about the "right" choice of indicators. Consequently, the term "lifestyle" covers a large spectrum of definitions and the respective research has very diverse foci. Some authors handle "lifestyle" as a dimension that is strongly characterised by freedom of choice and as a contrast to vertical stratification parameters like education and income [33]. Others see "lifestyle" as a synonym for household-characteristics [34] or point to certain behaviours as "lifestyle elements" [35]. Some try to characterize "the western lifestyle" [29], "lower-carbon lifestyles" [36], "low carbon lifestyles" [37], or pro-environmental lifestyles [32]. Furthermore, some point towards lifestyle changes on an aggregate level [38], or "consumer lifestyle" on a national level [30], just to name a few examples of the diversity of ways in which the term has been operationalised.

Secondly, the relationships between proxy variables and behaviour or behavioural impacts should not be seen as deterministic links. High environmental awareness in the sense of attitudes and intentions does not necessarily imply corresponding behaviour. This is caused by the fact that the relationships between such "predictor" variables and behaviour are influenced by a large variety of other variables, many of which are hardly accessible for empirical research. The resulting discrepancy between people's psychological predisposition with regard to environmental behaviour and their action is referred to as the "attitude-action gap" [39-42]. Reports from two Austrian projects which aimed at analysing energy-related lifestyles on a group level, illustrate a consequence of this problem. Both studies were conducted practically at the same time in the same country, and both aimed at identifying energy-relevant lifestyle groups. However, they obtained incommensurable and internally inconsistent results [43]. One of the studies [44] identified four groups with nearly identical energy use patterns and impacts. The other study [45] identified five groups with observable differences in 
their energy-related behavioural patterns, but with striking inconsistencies like "Disoriented Polluters" having the highest share of respondents using bicycles or public transport as their primary mode of transportation, and "Eco-Responsible" having the smallest share of daily cyclists. While the former used the energy-unspecific typology "Experience Milieus" [46], the latter used variables about energy-related attitudes, values and perspectives, similarly to an earlier German study [47]. However, as long as energy lifestyle segmentation does not reliably identify meaningful groups that significantly differ in their energy-relevant behaviour, the usefulness of group level analyses remains questionable.

Since a high congruency between awareness and action is the exception rather than the rule [48-50], group identification on the basis of awareness-related variables is problematic. At a first glance, the identification of groups based on a small selection of variables on respondent's pro-environmental and energy-saving behaviour seems a promising alternative. However, results obtained by this method raise doubts on this approach: for example the overall environmental footprints of "green" vs. "brown" consumers (identified by a selection of pro-environmental behaviours) turned out to not differ significantly in a 2012 study [51]. This phenomenon was entitled the "Behaviour-Impact Gap".

Another methodological strand is inspired by empirical findings that suggest a strong link between wealth and energy use/emissions, as, i.e., found by Lutzenhiser and Hackett [52]. The related "lifestyle" approach on the basis of economic input-output modelling operationalises "lifestyle" by using sociodemographic factors like household composition or family status and estimates energy use and emission as a function of expenditures $[30,53,54]$. However, the fact that estimations of that kind require economic information about all energy-relevant behaviour limits their practical applicability. For example, being a passenger in a car affects the energy and climate-specific behavioural impact of everyone on board, but the allocation of costs most commonly does not reflect the per-capita impact of the ride. Similarly, heating ones home with wood from a privately owned forest makes calculations based on expenditures impracticable and, if conducted, is prone to distortions caused by market changes.

In addition, there is another issue associated to the aforementioned problems: limited cross-national and longitudinal measuring equivalence, and thus, comparability (a well-known challenge in social science research) [55-57], is also a challenge in lifestyle research [33,58-61]. The diverse ways in which psychological characteristics translate into energy-relevant behaviour and how financial means translate into energy and climate impacts limit the measuring equivalence with regard to behaviour. For example, a group which is expected to have a large environmental impact due to its psychological characteristics or financial capabilities, may have a high impact in context A, but a relatively small impact in context $\mathrm{B}$ due to moderating factors. Therefore, typologies based on proxy variables do not only tend to be unreliable but are by design hardly comparable in terms of actual group-specific behaviour.

This indicates that three requirements must be met if meaningful groups with specific behavioural patterns of energy behaviour are to be identified:

(1) The energy lifestyle indicator shall not consist of psychological characteristics;

(2) The energy lifestyle indicator shall take into account as many aspects of energy relevant (private sphere) behaviour as possible; and

(3) The energy lifestyle indicator shall provide a reliable basis for comparing lifestyles between different countries and points in time.

\subsection{Limitation II: No Clear Distinction between Classifying and Explanatory Variables}

In lifestyle research, many authors (including ourselves) refer to Pierre Bourdieu, who defined "Life-Style" as "a system of classified and classifying practices (... )" [16]. Despite this emphasis on the fact that lifestyles are defined by particular practices, hardly any studies attribute them a pivotal role in the identification of lifestyles. More often, it is the case that variables that could actually be used as explanatory variables for behaviour are used for group identification. As mentioned above, this is especially problematic when psychological parameters are used as proxy-variables for the identification of groups expected to be different in their respective behaviour: Besides the problems 
caused by the above mentioned attitude-action gap, equating values and behaviour eliminates the chance for assessing the group-specific impact of psychological variables on behaviour. It seems likely that many efforts of that kind were guided by the aim of generating a holistic, but rather descriptive picture of different lifestyles. However, if the question about the driving factors behind different energy-relevant behavioural patterns should be addressed, the model development and analysis must strictly distinguish between classifying and explanatory variables.

\subsection{Addressing Limitations I \& II}

In order to provide the framework developed herein with structure, we mobilised a three-component understanding of what characterises a lifestyle, based on the work of Lüdtke [60]. These three components are "Performance", "Mentality" and "Situation". The details of these components are elaborated on in Table 1.

Table 1. Three components of "Lifestyle" according to Lüdtke (1996).

\begin{tabular}{cl}
\hline Performance & \multicolumn{1}{c}{ Facts of behaviour and relations to physical objects } \\
\hline Mentality & $\begin{array}{l}\text { Subjective perceptions like values, life-goals, preferences etc.; consisting } \\
\text { of a cognitive-motivational component and mental reflexions of the } \\
\text { current lifestyle-practice. }\end{array}$ \\
\hline Situation & $\begin{array}{l}\text { Objective context of life, including cultural and socioeconomic resources } \\
\text { and constraints. }\end{array}$ \\
\hline
\end{tabular}

\subsubsection{Specificity and Comparability}

To assess the driving factors behind different patterns of energy-relevant behaviour, we aimed to identify groups that differ as much as possible in their energy-related behaviour. In order to avoid the above-discussed problems related to the attitude-action gap, our approach was centred on the "Performance" component by identifying lifestyle groups based on the respondents' primary energy demands in different areas of life, expressed in the unit kilowatt-hours (kWh). These energy demand values were calculated based on self-reports about behaviour and equipment use (the actual "Performance" component of lifestyle). The energy-relevant categories of behaviour and equipment use were identified under consideration of climate scenarios based on demand side changes and behaviour change [21]. In order to categorise these behaviour related variables, we distinguished between the six areas of life "Housing", "Mobility", "Diet", "Consumer Goods", "Recreational Hobbies", and "Information". These six areas of life were chosen because the authors suggested that they provide a suitable basis to categorise energy-relevant behaviour and equipment use in a practicable way. They need a place to live, to move to and from work and other activities, something to eat, and clothes and other consumer items to support their life. In addition, in the modern world, a person needs to have forms of entertainment and knowledge. These are covered by "Recreational Hobbies" and "Information". Data on the respective behaviours were collected with relatively easy-to-answer survey questions resembling those used in carbon footprint calculators (The item battery that was developed as a part of the H2020-funded project "ECHOES" and used for a survey in 31 European countries is shown in Appendix A). In the development and pretesting of the questionnaire, particular attention was paid to keeping the number of "do not know" responses as low as possible. Respondents who were nevertheless unable to answer a certain question were either given the national average from an external data source (for example, for annual vehicle $\mathrm{km}$, the data availability is usually good) or they were assigned to the most frequent response category. The most essential feature of an energy lifestyle typology created by a clustering of individuals based on their energy impacts in different areas of life is the following: the clustering is based on variables that have a closer relationship to the energy-relevant behaviour than would be the case for proxy variables like values, attitudes, or pro-environmental behaviour. The deterministic relationship between behaviour and resulting energy demand causes a higher consistency between the (energy-)lifestyle indicator and the specific 
behaviour of the identified groups. The result is a more realistic typology of energy-relevant behavioural patterns. Therefore, the cluster solutions can be expected to differ considerably more in the groups' energy-relevant behaviour and impacts than what is the case with proxy models, which have shown to reveal groups with little or no differences in their energy demands or greenhouse gas emissions [44,45]. This expectation was supported by a typology generated with an impact-based approach for an Austrian sample [43]. The impact-based approach also has an advantage with regard to the comparability of resulting typologies: the relationship between certain behaviours and the resulting primary energy demand is deterministic, which means that the path between behaviour and the related consequence is known. For example, extensive mobility behaviour is associated with a high-energy impact in the area of mobility, regardless of the spatial or cultural context. Thus, behavioural typologies based on calculated impact estimations are better suited for cross-national comparisons and longitudinal studies than psychographic or proxy-behaviour-based typologies.

\subsubsection{Classifying vs. Explanatory Variables}

The second analytically beneficial difference between proxy models and the impact based approach presented herein is the strict distinction between the variables of primary interest (energy-relevant behaviour and related impacts) that are used for group identification, and variables that can be used to explain the respective behavioural patterns (e.g., psychological characteristics, sociodemographics, context parameters). This distinction broadens the range of feasible analytical procedures beyond the mainly descriptive discussion of group characteristics, as it allows a better quantitative analysis of the driving factors behind different patterns of behaviour. In proxy-based models, by contrast, the choice of explanatory variables is very limited by default. Since the fundamental assumption of a strong relationship between attitudes and behaviour is the basis for group assignment there, e.g., the influence of attitudes on behaviour cannot be analytically addressed due to circular reasoning. In the impact-based process, instead, all the variables that do not measure concrete behaviour or equipment use might be used as explanatory variables for energy-relevant behaviour. Thus, the components "Mentality" and "Situation" are fully available for the explanation of lifestyle-specific energy behaviour and related impacts. Although their suitability for group identification is limited, they play a crucial role for understanding the driving factors behind different forms of energy behaviour [39-42].

\subsection{Limitation III: Focus on Households Instead of Individuals}

Since the above mentioned "classified and classifying practices" [16] can be performed by both individuals and by micro-groups like households, the term "lifestyle" is, by definition, open for individual and household levels. However, the framework presented herein aimed to analyse individual-level behaviour. The reasons for this focus are described in the following section.

Seebauer and colleagues demonstrated that using individual responses as a proxy for the total household is problematic due to limited accuracy and consistency in answers about other household members' behaviours [62]. Vice versa, using household-specific data as proxy for individual behaviour or behavioural impact must also be considered problematic. For example, Bohunovsky and colleagues calculated per capita energy use and emissions for a variety of activities based on household level energy/emission data and the number of household members [44]. This method allows a reasonable estimation of the energy demand and emissions for some in-house behaviours like space heating or cooling, since they are widely characterised by the sharing of resources by different household members. However, as soon as more individual decisions and everyday practices come into play, the household level does not provide a sufficient data basis about individual lifestyles of different household members (e.g., How much meat does one eat? Where does he or she work or study? Which mode of transportation does the individual use?). For a number of individual characteristics and lifestyle-related behaviours, considering households as internally consistent entities is problematic. This is the case for sociodemographics (e.g., age, sex, education, individual disposable income, etc.) as well as for behavioural patterns, attitudes, preferences, life goals, etc. Therefore, research with the aim 
of identifying groups of people with specific lifestyle-related behavioural patterns and impacts should focus on the life of the individual respondent in most areas of life. We are aware that individuals are also not completely independent from their social context. However, individuals can provide more valid information about their own lives than about other household members. Thus, we preferred to ask for individual behaviour and control for effects through household composition instead of collecting "household"-specific information from individuals with the aim of inferring back on an "average household member".

\subsection{Addressing Limitation III}

A focus on the individual was applied in the study presented by Notter and colleagues, for example. It is based on individual lifestyle data from the "Swiss Environmental Survey 2007" and features calculations of energy use, $\mathrm{CO}_{2}$ emissions and the EI99 index bottom-up, using the method of Life Cycle Assessment (LCA) [29]. The main advantage of the lifecycle perspective is that it does not take an isolated view on individual behaviour or equipment use but also takes macro-level factors into account when estimating the associated energy impact. These factors include, in particular, the shares of fossil and renewable sources in the generation of electricity used in the respective country or region.

By collecting and using decidedly individual-specific data wherever practicable and useful, the framework developed herein had a clear focus on the behaviour of individuals throughout the research process. With regard to the "Performance" component (Table 1), this is the case for all areas of life except for data related to the shared use of resources in the home, where per-capita averages are used because the individual shares of space and heat use cannot be reasonably estimated in most cases. In the "Mentality" component, which serves as an explanatory dimension for individual energy behaviour, scales for individual psychological characteristics as well as items with a focus on how environmental issues are discussed in the respondents' household or personal networks might be of interest. Data on the "Situation" of the respondents can comprise explicitly individual variables such as age, gender, educational level, occupation, individual income, as well as household-related variables like the number of residents, household income, and structural variables like the place of residence.

\section{Materials and Methods: Introducing the Impact-Based Lifestyle Research Framework}

In the following section, the procedure outlined above is described step by step in the form of an analytical framework (which is depicted in Figure 1), starting with the collection of the data required to identify impact-based lifestyles.

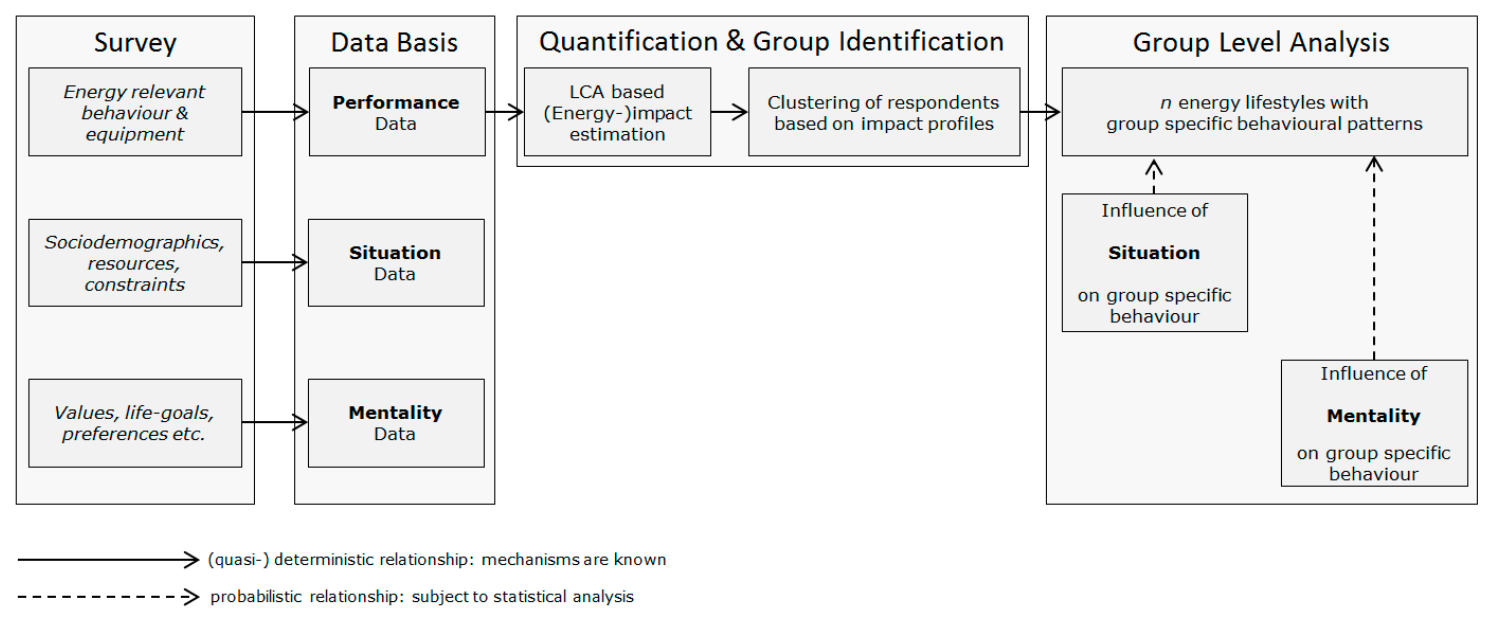

Figure 1. Illustration of the research process. Collection of data on "Performance", "Situation" and "Mentality" (source: own depiction). 
Presently, "Performance" in terms of energy-relevant behaviour across all main areas of life is not covered by any larger survey-panel. Therefore, there is currently no consensus on how such data are to be collected and the experience with such data collection is limited. However, since the estimation of group-specific energy and climate impacts based on data about behaviour is one of the central aims of energy lifestyle research, the question about how to gather such information about individuals has already been discussed in the literature. For example, Bohunovsky and colleagues collected data on direct energy use by computer-assisted personal interviews and found that the majority of respondents were unable to provide accurate information on their energy consumption. Instead, information about behaviour, equipment use and characteristics of their home was more easily available to the respondents. Therefore, the authors used this kind of information and calculated energy use and emissions on that basis [44].

The approach of impact-based lifestyle research understands "Performance" as all kinds of behaviour with implications for an individual's energy consumption. With regard to quantifying the energy consumption, one option is to focus on direct energy use, such as the fuel needed when driving a car or the electricity needed for using an electric device, for example. Alternatively, one can take a life cycle perspective, which also takes the additional amount of energy into account that is required for the provision of the respective products or services. Since the consequences of energy use (such as greenhouse gas emissions) are not limited to the use phase, we consider the life cycle perspective appropriate here. Therefore, any activities can be considered energy-relevant as soon as either energy is utilised directly or products or services are used that require energy in their provision. The lifecycle perspective was also chosen by Notter and colleagues [29]. (A detailed documentation of the LCA based estimation of individual energy demands, as conducted in the project "ECHOES", can be downloaded as Supplementary Materials.)

As stated above, the group identification in the impact-based approach is fully based on variables related to "Performance", which means that the type and combination of potential explanatory variables regarding "Situation" and "Mentality" are widely open for the individual research interest. While the choice of variables about the individual "Situation" is likely to be dominated by sociodemographic characteristics, the variety of potentially interesting "Mentality" parameters is large. Many well tested and documented psychological scales about attitudes, intentions, world-views, self-efficacy, etc., are available. Analysing groups with actual differences in energy-related behavioural patterns promises new valuable insights into the role of different psychological and structural parameters for technology choices and group-specific potentials for energy transition and climate change mitigation. However, before such group level analyses can be conducted, energy lifestyle groups need to be identified.

\subsection{Group Identification Based on "Performance" Data}

In accordance to the understanding of lifestyle as "a system of classified and classifying practices" [16], data on individual behaviour and equipment use need to be transformed into an indicator for the identification of energy lifestyle groups. In addition to the large number of potential indicator variables, there is also the question of their weighting. What makes this large variety and the weighting-problem manageable is the fact that all of these parameters are deterministically connected to the amounts of energy needed for different behaviours and consumption activities. Therefore, these energy amounts can be used as an impact currency, which provides information about the energy intensity of someone's behaviour. This impact currency was calculated on the basis of data on behaviour and equipment use using ISO standardised Life Cycle Assessment methodology [63] which is a procedure that largely corresponds to an estimation of the full carbon footprint "Tier/Scope III" [64]. As reflected in Figure 2, the variety of energy impacts from behaviour and equipment use can be summarised into six distinct areas of life, namely Housing, Mobility, Consumption, Diet, Leisure, and Information, as described by Bird et al. [65]. This reduction of dimensions results in an energy lifestyle indicator set of six impact-variables. Based on these six impact-variables, individuals can be clustered according to similarities in their impact patterns across the six main areas of life. 


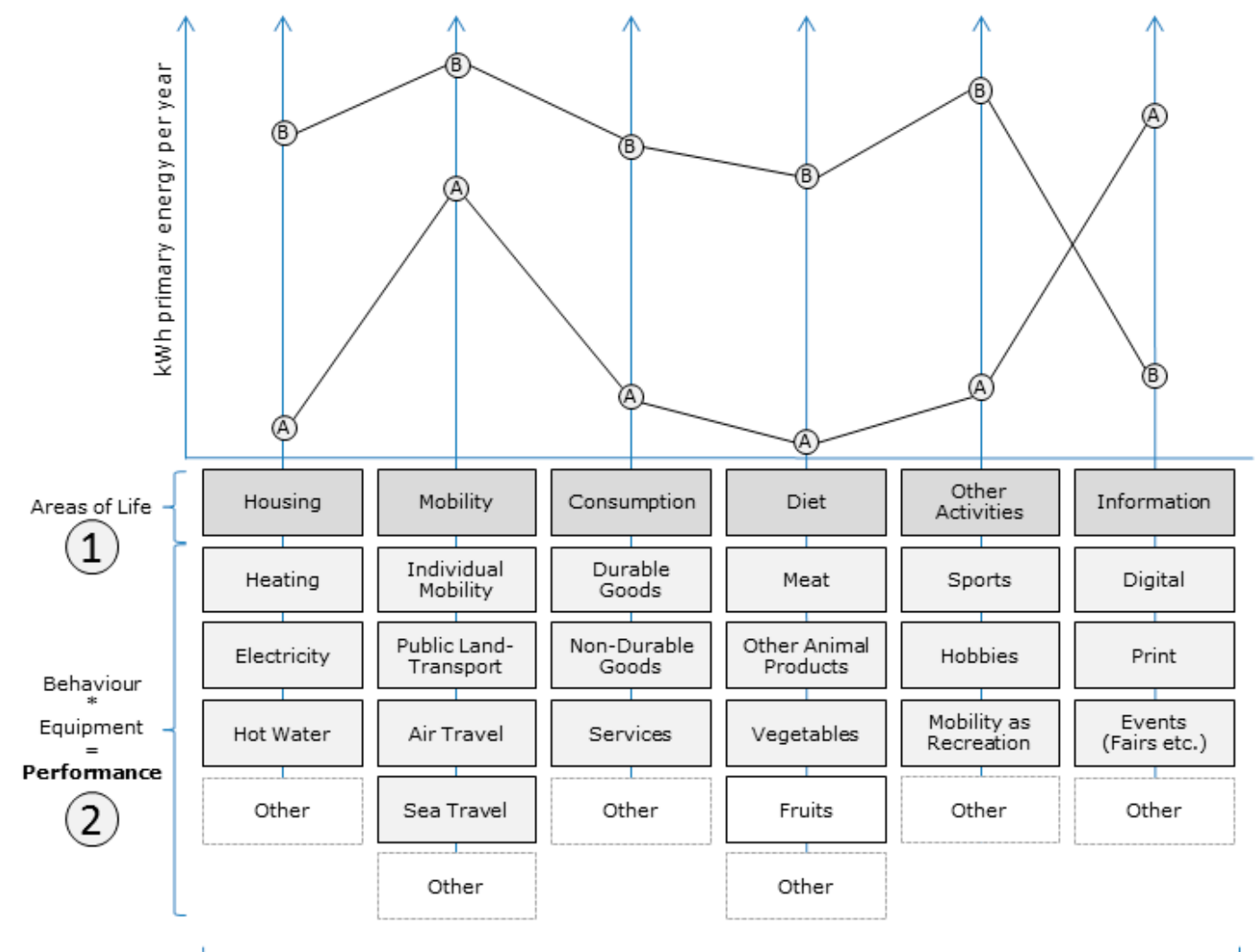

(3) Situation \& Mentality

(4) Context

Figure 2. Illustration of the impact-based lifestyle research framework developed herein. Profiles " $\mathrm{A}$ " and " $\mathrm{B}$ " represent the LCA-estimated energy-impact patterns of fictional groups (for illustration purposes only; source: own depiction).

Given the fact that the six indicator variables each reflect an estimate of primary energy demand in one of the six areas of life, they can be considered metric variables. This offers a large number of potentially applicable clustering methods. However, the results obtained from clustering can largely depend from the algorithm choice itself as well as from a variety of decisions to be made on their use (especially the distance measure and the number of clusters). The objective of being able to compare between lifestyle clustering results at different times or in different countries suggests the use of an algorithm with a minimum of choices to be made. The Two-Step Cluster Analysis, delivered with IBM SPSS and available for R Statistics as a part of the package prcr, is based on such a relatively user-friendly algorithm and was shown to perform well if used with continuous variables [66]. The choice of a distance measure is relatively simple and a suggestion of a reasonable number of clusters can be created automatically based on the AIC or BIC information criterion [67].

After deciding on a certain number of clusters, the primary energy demand patterns of the identified clusters (like the fictitious profiles A and B in Figure 2) provide the first hints regarding the group-typical behavioural patterns and equipment use ("Performance"). In the 31-country analysis conducted in the Horizon 2020 funded project ECHOES, a solution with six groups was chosen as a "reasonable balance between number of groups and interpretability" [68]. The identified groups can be characterised on a descriptive basis and the statistical analysis of the driving factors behind different patterns of energy behaviour and behavioural impact can be conducted by using the components "Situation" and "Mentality" as predictors for energy-lifestyle group assignment. 


\subsection{Group Characterisation, Analysis of Driving Factors and the Role of the "Context"}

In a first step, the groups identified during the cluster analysis can be roughly characterised by interpreting their energy demand profiles and underlying behaviour in combination with other variables that qualitatively describe the group. In such a descriptive characterisation, e.g., information on the housing situation, mobility behaviour, family status, age and gender distribution, professional status, and information about common technologies used by group members can be included.

For the purpose of statistically assessing the driving factors behind group-specific behaviour, our experience in the course of the "ECHOES" project has shown that in terms of interpretation, it is favourable to model the odds for a group membership for each group in a binary logistic regression according to the scheme " 1 = group membership, $0=$ no group membership", by using "situation" and "mentality" variables as predictors. [68] This illustrates well how the respective group differs from the rest of the sample in terms of the driving factors behind its specific energy behaviour. If a comparison to a certain groups is of interest, bi- or multinomial logistic regression with a specific group instead of the remaining sample might be used as reference category.

Ultimately, the physical, spatial, cultural, legal and economic "Context" (4) in which all human action occurs is similarly important for the understanding of how "Situation" and "Mentality" influence the energy-relevant behaviour on the aggregate and group level. Thus, relevant context parameters must be taken into account in both research planning and interpretation of results. In terms of interpretation, a thorough consideration of the context can be extraordinarily important for understanding e.g., differences between countries that cannot be explained by "Situation" and "Mentality" variables alone. This could, e.g., be the case when a certain region has a specific legal/political framework with extensive funding of certain technologies, while such funding is not available in another national entity.

\section{Discussion and Conclusions}

Within the broad and multidisciplinary research field focusing on sustainability transitions, the concept of lifestyles largely seems to be forgotten. In this article, we aimed to re-introduce the concept into such discussions through the presentation of a rigorous methodological and theoretically informed framework, which allows for analysis of what we call impact-based energy lifestyles. Our approach has a series of scholarly benefits, as well as potential implications for the development of policies and other interventions that target lifestyle changes.

The presented framework is based on the identification of energy lifestyle groups via similarities and dissimilarities in individual primary energy use profiles that are estimated based on survey-collected self-reports on behaviour and equipment use using LCA methodology. This form of group identification addresses some main criticism towards lifestyle research in general [61] and towards its application in the field of energy behaviour [69]. Other than group identification on the basis of psychological characteristics (which is especially problematic due to the attitude-action gap [40], the impact-based approach uses an indicator which is less prone to being biased by uncontrollable context-effects. An individual's primary energy demands in different areas of life have (in empirical reality) deterministic links to the individual's behavioural patterns and equipment use. Instead, psychological characteristics are only statistically connected to behaviour and thus likely to result in unreliable results with regard to the behaviour of identified groups. This makes primary energy demands a better basis for the identification of groups that have specific behavioural patterns and the latter a reasonable choice for the analysis of group-specific behaviour in statistical models.

Altogether, the impact-based form of group identification has three main scholarly advantages: Firstly, it makes sure that the identified groups differ in their energy-related behaviour and not primarily in their energy-related psychological characteristics. Secondly, the estimation of energy demand with the means of lifecycle assessment based on behaviour/equipment use is based on a logic that remains widely constant over time and in different regional or national contexts. Therefore, the longitudinal and cross-sectional comparability of results obtained by the impact-based form of lifestyle research can 
be considered higher. Thirdly, by disconnecting the lifestyle group identification from all variables that potentially explain behaviour, the range of parameters that can be used to understand group-specific behaviour is extended.

With regard to the survey effort, the data required for a reasonable estimation of the behavioural energy impact can, depending on the regional context, be collected with a number of around 40 items, which is in the usual range for lifestyle indicators [58]. The option to modify or extend the list of energy-related sub-categories while maintaining the basic structure of the indicator along six areas of life allows the approach to be applied in other regions of the world with fundamentally different environmental conditions and technologies. However, the validity of self-reported behaviour should always be validated in the respective region before the approach comes to use, e.g., in a longitudinal survey-panel. The item battery that was developed to be used in 31 European countries as a part of the aforementioned H2020-funded project "ECHOES" is shown in Appendix A.

At a whole, the quantification of lifestyle impacts and the systematic consideration of explanatory variables from the components "Situation" and "Mentality" provides a helpful structure for the analysis of the driving factors behind energy-relevant behaviour of relevant societal groups and for the design of target-group-oriented policies and interventions that address multiple areas of life. The expected increase in longitudinal and cross-national comparability promises an improved basis for the design of target-group-oriented policy measures and could provide an additional starting point for group-level research on the Jevons Paradox and rebound effects [70]. By making not only patterns of behaviour but also patterns of responsibility more accessible, the introduced approach for energy lifestyle research might deliver a contribution to the brisk discourse about consumption-based accounting of greenhouse gas emissions [71,72].

Ultimately, we hope that this relatively straightforward method of group identification will foster the finding of a consensus in the question of how energy-specific lifestyle groups can be best identified and facilitate the build-up of a cumulative knowledge base about the energy and climate relevance of different lifestyles.

Supplementary Materials: The following are available online at http://www.mdpi.com/2071-1050/11/21/6162/s1.

Author Contributions: Conceptualization, social science methodology and visualisation, S.S.; SSH related theoretical background, S.S. and T.M.S.; LCA-based impact assessment methodology, D.N.B.; writing, S.S. and T.M.S.; English proof reading, D.N.B.

Funding: The work presented in this paper was funded as part of the project "ECHOES" (Energy CHOices supporting the Energy union and the Set-plan) by the European Union under "H2020-EU.3.3.6. Robust decision making and public engagement".

Acknowledgments: The methodological framework presented herein provided the basis for the lifestyle research conducted in the aforementioned Horizon 2020 project, covering 31 European countries. We would like to thank all ECHOES colleagues who attended the general assembly in San Sebastian in September 2017 for their extensive feedback on an early draft of the impact-based approach. Special thanks to Markus Hadler, Petra Königshofer, Maria Hingsamer, Markus Schweighart and Sebastian Seebauer for their feedback on draft versions of this paper.

Conflicts of Interest: The authors declare no conflict of interest.

\section{Appendix A}

The following section contains our suggested item battery for surveying the "performance" component of respondents' energy-related lifestyles. The questions were selected considering a severe survey time constraint since the survey was part of a much larger energy survey. This had an impact on the number of questions and, as such, the responses should be considered indicators of behaviour. The questions are the result of a considerable pretest and modification effort and were designed with the aim of achieving a good trade-off between simplicity (in order to achieve a reasonable response-rate) and level of detail in order to provide a basis for LCA-based impact estimation. For the methodological details of an LCA-estimation on the basis of the attached questionnaire, see Bird et al. [65]. For example, for consumption of clothing, we asked only one question and did not distinguish between different articles of clothing (e.g., shoes). One must remember that the gross values for each of the six areas have 
significant differences in magnitude. However, for the purpose of lifestyle identification in the ECHOES project, a relative approach was chosen in which the six variables were converted to standardised variables and each area was given the same weight. If you intend to conduct an impact-based approach, always make sure to modify the questionnaire in order to ensure that behaviour and technological choices common in the respective region are covered (e.g., sea-travel in a region where ferries are a common means of public transport).

How many km per year do you drive a car as a driver (privately incl. driving to work)?

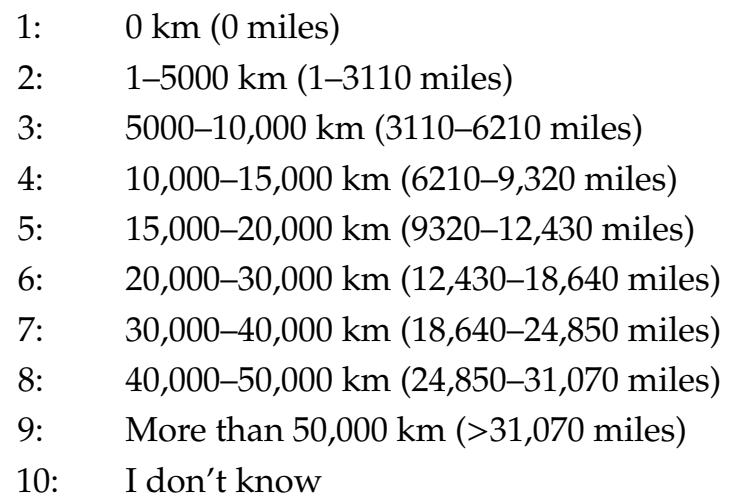

Q76 How often do you drive alone in the car? (For private purposes - including trips between your home and working place)

$\begin{array}{ll}\text { 1: } & \text { Almost never } \\ \text { 2: } & \text { Rarely } \\ \text { 3: } & 50 \% \text { of time } \\ \text { 4: } & \text { Very often } \\ \text { 5: } & \text { Almost always }\end{array}$

Q77 How many people in total are usually in the car when you are the driver? (For private purposes including trips between your home and working place.)

$\begin{array}{ll}\text { 1: } & 1 \\ \text { 2: } & 2 \\ \text { 3: } & 3 \\ \text { 4: } & 4 \\ \text { 5: } & 5 \text { or more }\end{array}$

Q78 What type of propulsion does the private car you most commonly use have?

$\begin{array}{ll}\text { 1: } & \text { Petrol } \\ \text { 2: } & \text { Diesel } \\ \text { 3: } & \text { Hybrid-electric } \\ \text { 4: } & \text { Plug-in Hybrid } \\ \text { 5: } & \text { Fully Electric } \\ \text { 6: } & \text { Gas } \\ \text { 7: } & \text { I don't know }\end{array}$

Q79 What is the fuel consumption you have with your most commonly used car? (privately incl. driving to work).

1: $\quad 3-5$ L (0.66-1.10 Imp. gal) 
2: $\quad$ 5-7 L (1.10-1.54 Imp. gal)

3: $\quad$ 7-10 L (1.54-2.20 Imp. gal)

4: $\quad$ 10-12 L (2.20-2.64 Imp. gal)

5: $\quad 12$ or more L (2.64 or more Imp. gal)

Q80 What is the average distance you can drive with a fully charged battery?

1: $\quad$ up to $100 \mathrm{~km}(<62$ miles $)$

2: $\quad$ 100-150 km (62-93 miles)

3: $\quad$ 150-200 km (93-124 miles)

4: $\quad 200-250 \mathrm{~km}$ (124-155 miles)

5: $\quad 250-300 \mathrm{~km}(155-186$ miles $)$

6: $\quad 300-400 \mathrm{~km}$ (186-249 miles)

7: $\quad$ More than $400 \mathrm{~km}$ (> 2249 miles)

Q81 How many $\mathrm{km}$ per year do you ride a motorbike or scooter (privately incl. driving to work)?

1: $\quad 0 \mathrm{~km}(0$ miles $)$

2: $\quad 1-2500 \mathrm{~km}(1-1550$ miles $)$

3: $\quad 2500-5000 \mathrm{~km}(1550-3110$ miles $)$

4: $\quad 5000-7000 \mathrm{~km}(3110-4350$ miles $)$

5: $\quad 7000-10,000 \mathrm{~km}(4350-6210$ miles $)$

6: $\quad 10,000-12,500 \mathrm{~km}(6210-7770$ miles $)$

7: $\quad 12,500-15,000 \mathrm{~km}$ (7770-9320 miles)

8: $\quad 15,000-20,000 \mathrm{~km}(9320-124,300$ miles $)$

9: $\quad$ More than $20,000 \mathrm{~km}$ (more than 12,430 miles)

10: I don't know

Q82 What is the fuel consumption of your most commonly used motorbike or scooter? (privately incl. driving to work)

1: $\quad 1-2$ L $(0.22-0.44$ Imp. gal)

2: $\quad 2-4 \mathrm{~L}(0.44-0.88$ Imp. gal)

3: $\quad 4-5 \mathrm{~L}(0.88-1.10 \mathrm{Imp}$. gal)

4: $\quad$ 5-7 L (1.10-1.54 Imp. gal)

5: $\quad 7$ or more L (1.54 or more Imp. gal)

6: $\quad$ It is electric

7: $\quad$ I don't know

Q83 For how many trips per week are you a passenger in a private vehicle?

$\begin{array}{ll}\text { 1: } & 0 \\ \text { 2: } & 1-2 \\ \text { 3: } & 3-4 \\ \text { 4: } & 5-6 \\ \text { 5: } & 7 \text { or more }\end{array}$

Q84 When you are a passenger in a private vehicle, how many people including yourself are usually in the car?

1: $\quad 2$

2: 3

3: 4 
4: 5

5: $\quad 6$ or more

Q85 Which type(s) of public transportation do you use as a part of your routine mobility? (please choose all that apply)

1: $\quad$ Bus

2: $\quad$ Train

3: $\quad$ Tram or streetcar

4: $\quad$ Underground

5: $\quad$ None of the above

Q86 How many minutes do you spend on the Bus on an average weekday?

1: $\quad 1-10$ minutes a day

2: $\quad 11-20$ minutes a day

3: $\quad 21-40$ minutes a day

4: $\quad 41-60$ minutes a day

5: $\quad$ More than 60 minutes a day

6: I do not use the bus regularly.

Q87 How many minutes do you spend on the Train on an average weekday?

1: $\quad 1-10$ minutes a day

2: $\quad 11-20$ minutes a day

3: $\quad 21-40$ minutes a day

4: $\quad 41-60$ minutes a day

5: $\quad$ More than 60 minutes a day

6: I do not use the train regularly.

Q88 How many minutes do you spend on the Tram on an average weekday?

1: $\quad 1-10$ minutes a day

2: $\quad 11-20$ minutes a day

3: $\quad 21-40$ minutes a day

4: $\quad 41-60$ minutes a day

5: $\quad$ More than 60 minutes a day

6: I do not use the tram regularly.

Q89 How many minutes do you spend on the Underground on an average weekday?

1: $\quad 1-10$ minutes a day

2: $\quad 11-20$ minutes a day

3: $\quad 21-40$ minutes a day

4: $\quad 41-60$ minutes a day

5: $\quad$ More than 60 minutes a day

6: I do not use the undergound regularly.

Q90 Please choose the answer that best describes your bicycle use.

1: $\quad$ I almost never go to work or shopping by bike.

2: $\quad$ I rarely go to work or shopping by bike.

3: I sometimes go to work or shopping by bike.

4: I usually go to work or shopping by bike during the warm season. 
5: $\quad$ I usually go to work or shopping by bike during winter.

6: I usually go to work or shopping during whole year

Q91 Please choose the response that fits your opinion about carsharing the best. By carsharing we mean a very short (hourly) to long (days) rental of cars, operated by companies or private initiatives. Usually accessible at all hours and located close to the user.

1: $\quad$ Not tried it and not interested.

2: $\quad$ Not tried it, but it sounds interesting.

3: $\quad$ Tried it and liked it.

4: $\quad$ Tried it and did not like it.

Q92 About how many hours have you spent on private flights, for purposes like holidays, over the past year?

1: $\quad 0$

2: $\quad$ less than 3 hours

3: $\quad$ between 3 and 6 hours

4: $\quad$ between 6 and 10 hours

5: $\quad$ between 10 and 15 hours

6: $\quad$ between 15 and 20 hours

7: $\quad$ between 20 and 25 hours

8: $\quad$ between 25 and 30 hours

9: $\quad$ more than 30 hours

Q93 Did you take any business trips by plane during the past year?

$$
\begin{array}{ll}
\text { 1: } & \text { No, I did not. } \\
\text { 2: } & \text { Yes, } 1-2 \\
\text { 3: } & \text { Yes, } 3-4 \\
\text { 4: } & \text { Yes, } 5 \text { or more }
\end{array}
$$

Q94 In what type of house do you live?

$$
\begin{array}{ll}
\text { 1: } & \text { Single-family house } \\
\text { 2: } & \text { Farmhouse } \\
\text { 3: } & \text { Semi-detached or terraced home } \\
\text { 4: } & \text { Flat in block with up to } 10 \text { dwellings } \\
\text { 5: } & \text { Flat in block with more than } 10 \text { dwellings } \\
\text { 6: } & \text { Other }
\end{array}
$$

Q95 How much indoor living space does your household have?

$$
\begin{array}{ll}
\text { 1: } & 30 \mathrm{~m}^{2} \text { or less (223 sqft or less) } \\
\text { 2: } & 31-50 \mathrm{~m}^{2} \text { (224-538 sqft) } \\
\text { 3: } & 51-70 \mathrm{~m}^{2} \text { (539-753 sqft) } \\
\text { 4: } & 71-90 \mathrm{~m}^{2} \text { (754-969 sqft) } \\
\text { 5: } & 91-110 \mathrm{~m}^{2} \text { (970-1184 sqft) } \\
\text { 6: } & 111-130 \mathrm{~m}^{2}(1185-1399 \mathrm{sqft}) \\
7: & 131-150 \mathrm{~m}^{2}(1400-1615 \mathrm{sqft}) \\
\text { 8: } & 151-170 \mathrm{~m}^{2}(1616-1830 \mathrm{sqft}) \\
\text { 9: } & 171-190 \mathrm{~m}^{2}(1831-2045 \mathrm{sqft}) \\
\text { 10: } & \text { more than } 190 \mathrm{~m}^{2} \text { (more than 2045 sqft) }
\end{array}
$$




\section{1: I don't know}

Q96 How is your home primarily heated?

1: $\quad$ Central heating (in the house) for the whole dwelling

2: $\quad$ District heating (heat provided to several or many houses by a larger heating plant)

3: $\quad$ One or more standalone stoves

4: $\quad$ One or more standalone electric heaters

5: I don't know

Q97 Do you know what your primary heating fuel is?

$\begin{array}{ll}\text { 1: } & \text { Coal } \\ \text { 2: } & \text { Gas } \\ \text { 3: } & \text { Oil } \\ \text { 4: } & \text { Wood } \\ \text { 5: } & \text { Electricity } \\ \text { 6: } & \text { Heat Pump-Geothermals } \\ \text { 7: } & \text { Heat Pump-Air } \\ \text { 8: } & \text { Solarthermals } \\ \text { 9: } & \text { Other } \\ \text { 10: } & \text { I don't know }\end{array}$

Q98 What do you think about your preferred room temperature setting compared to other people you know in your country?

$\begin{array}{ll}\text { 1: } & \text { much cooler } \\ \text { 2: } & \text { slightly cooler } \\ \text { 3: } & \text { about average } \\ \text { 4: } & \text { slightly warmer } \\ \text { 5: } & \text { much warmer } \\ \text { 6: } & \text { I don't know }\end{array}$

Q99 How often do you use air condition at home during the summer?

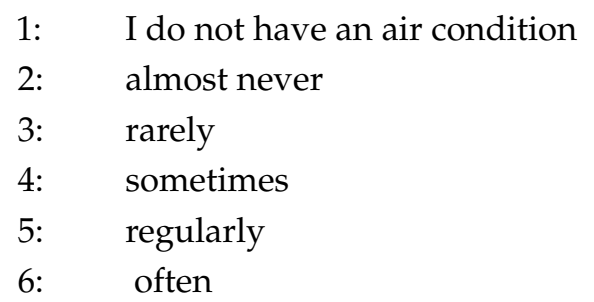

Q100 When was the house in which you live built? Your best estimate will be fine.

$\begin{array}{ll}\text { 1: } & 1900 \text { and before } \\ \text { 2: } & 1901-1920 \\ \text { 3: } & 1921-1940 \\ \text { 4: } & 1941-1960 \\ \text { 5: } & 1961-1980 \\ \text { 6: } & 1981-2000 \\ \text { 7: } & \text { After 2000 } \\ \text { 8: } & \text { I don't know }\end{array}$

Q101 Have energy efficiency renovations been made to your dwelling? (Select all that apply) 
1: $\quad$ No

2: Outside-walls insulation

3: Roof insulation

4: $\quad$ Cellar ceiling insulation

5: Windows retrofitted

6: $\quad$ Top floor ceiling insulation

7: I don't know

Q102 How often do you disconnect electric appliances from the power supply when you are currently not using them? (Specifically TV, PC, Notebook, DVD-Player etc.)

1: $\quad$ never

2: $\quad$ rarely

3: occasionally

4: $\quad$ often

5: $\quad$ always

Q103 What proportion of your light bulbs at home are energy saving varieties (e.g. LED, compact fluorescent, etc.)?

1: $\quad$ zero or only a few

2: $\quad$ several

3: $\quad$ most (around $75 \%)$

4: $\quad$ all $(100 \%)$

5: I don't know

Q104 Do you purchase your electricity from a provider with a particularly high share of renewable energy production?

1: $\quad$ No

2: $\quad$ Yes

3: I don't know

Q105 How many warm meals do you personally eat per week?

1: $\quad 0-1$

2: $\quad 2-5$

3: $\quad 6-9$

4: $\quad 10-13$

5: 14 or more

Q106 Please choose the answer that best describes your diet.

1: $\quad$ Meat in most meals

2: $\quad$ Meat in some meals

3: $\quad$ Meat very rarely

4: $\quad$ No meat, but fish

5: Vegetarian

6: Vegan

Q107 How is hot water provided in your home?

1: $\quad$ Electric

2: $\quad$ Solar-thermal 
$\begin{array}{ll}\text { 3: } & \text { Oil } \\ \text { 4: } & \text { Gas } \\ \text { 5: } & \text { District heating } \\ \text { 6: } & \text { Geo-thermal } \\ \text { 7: } & \text { Other } \\ \text { 8: } & \text { I don't know }\end{array}$

Q108 Do you have a bathtub?

1: $\quad$ Yes

2: $\quad$ No

Q109 What do you choose more often?

1: $\quad$ taking a bath

2: $\quad$ taking a shower

3: $\quad$ use both equally

Q110 Please choose the answer that best fits your most common hobbies and leisure activities.

1: $\quad$ Very little equipment and infrastructure needed (e.g. playing board games, reading, ... )

2: $\quad$ Little equipment and infrastructure needed (e.g. playing music, hiking, cycling ... )

3: $\quad$ Moderate amount of equipment and infrastructure (e.g., computer games, photography, ... )

4: $\quad$ More equipment and infrastructure needed (e.g., skiing, team sports, ... )

5: $\quad$ A lot of equipment and infrastructure needed (e.g., motorsports, heli-skiing, ... )

Q111 Please choose the answer that best describes your preferences in fashion.

1: $\quad$ Modest

2: $\quad$ Long use, also second hand

3: $\quad$ About average

4: $\quad$ New clothes quite often

5: $\quad$ Highly fashionable, always the latest style

Q112 Please choose the answer that best fits your preferences in purchasing electronics (PC, Notebook, Tablet, Smartphone, TV, Hi-Fi Equipment)

1: $\quad$ I do not need most of it

2: $\quad$ Long use, replace only if broken

3: $\quad$ About average

4: $\quad$ New equipment regularly

5: I like to always have the latest technology

Q113 Please choose the answer that best describes your private usage of electronics. (PC, Notebook, Tablet, Smartphone, TV, Hi-Fi Equipment)

1: $\quad$ I use electronics very little

2: $\quad$ I use electronics less than most others

3: I use electronics about average

4: I use electronics quite intensively

5: $\quad$ I use electronics very intensively. 


\section{References}

1. Geels, F.W.; Sovacool, B.K.; Schwanen, T.; Sorrell, S. Sociotechnical transitions for deep decarbonization. Science 2017, 357, 1242-1244. [CrossRef] [PubMed]

2. Schot, J.; Kanger, L. Deep transitions: Emergence, acceleration, stabilization and directionality. Res. Pol. 2018, 47, 1045-1059. [CrossRef]

3. Van Exter, P.; Blok, K.; Terlouw, W. Energy transition within $1.5^{\circ} \mathrm{C}$ : A disruptive approach to $100 \%$ decarbonisation of the global energy system by 2050. Available online: https://www.navigant.com/-/media/ www/site/downloads/energy/2018/navigant2018energytransitionwithin15c.pdf (accessed on 31 October 2019).

4. Van Vuuren, D.P.; Stehfest, E.; Gernaat, D.E.H.J.; Doelman, J.C.; van den Berg, M.; Harmsen, M.; de Boer, H.S.; Bouwman, L.F.; Daioglou, V.; Edelenbosch, O.Y.; et al. Energy, land-use and greenhouse gas emissions trajectories under a green growth paradigm. Global Environ. Chang. 2017, 42, 237-250. [CrossRef]

5. Van Vuuren, D.P.; van Soest, H.; Riahi, K.; Clarke, L.; Krey, V.; Kriegler, E.; Rogelj, J.; Schaeffer, M.; Tavoni, M. Carbon budgets and energy transition pathways. Environ. Res. Lett. 2016, 11. [CrossRef]

6. Geels, F.W. Technological transitions as evolutionary reconfiguration processes: A multi-level perspective and a case-study. Res. Pol. 2002, 31, 1257-1274. [CrossRef]

7. Schot, J.; Geels, F.W. Strategic niche management and sustainable innovation journeys: Theory, findings, research agenda, and policy. Tech. Anal. Strat. Manag. 2008, 20, 537-554. [CrossRef]

8. Shove, E.; Walker, G. CAUTION! Transitions ahead: politics, practice, and sustainable transition management. Environ. Plann. 2007, 39, 763-770. [CrossRef]

9. Røpke, I. Sustainable Consumption: Transitions, Systems and Practices. In Handbook of Ecological Economics; Edward Elgar Publishing: Cheltenham, UK, 2015; pp. 332-359.

10. Aune, M.; Godbolt, Å.L.; Sørensen, K.H. Mismatch or misunderstanding? Calculation and qualculation among economists and consumers in their framings of the electricity market. Acta Sociologica 2016, 59, 347-361. [CrossRef]

11. Schot, J.; Kanger, L.; Verbong, G. The roles of users in shaping transitions to new energy systems. Nat. Energy 2016, 1, 16054. [CrossRef]

12. Ryghaug, M.; Skjølsvold, T.M.; Heidenreich, S. Creating energy citizenship through material participation. Soc. Stud. Sci. 2018, 48, 283-303. [CrossRef]

13. Seyfang, G.; Haxeltine, A. Growing Grassroots Innovations: Exploring the Role of Community-Based Initiatives in Governing Sustainable Energy Transitions. Environ. Plann. C. Govern. Pol. 2012, 30, 381-400. [CrossRef]

14. Anable, J.; Brand, C.; Eyre, N.; Layberry, R.; Bergman, N.; Strachan, N.; Fawcett, T.; Tran, M. Lifestyle and Energy Consumption; UK Energy Research Centre: London, UK, 2011.

15. Reusswig, F. Sustainability Transitions Through the Lens of Lifestyle Dynamics. In Sustainable Production Consumption Systems: Knowledge, Engagement and Practice; Lebel, L., Lorek, S., Daniel, R., Eds.; Springer: Berlin, Germany, 2010; pp. 39-59.

16. Bourdieu, P. Distinction: A Social Critique of the Judgement of Taste; Harvard University Press: Cambridge, MA, USA, 1987.

17. Schipper, L.; Bartlett, S.; Hawk, D.; Vine, E. Linking Life-Styles and Energy Use: A Matter of Time? Annu. Rev. Energ. 1989, 14, 273-320. [CrossRef]

18. Rotmans, J.; Kemp, R.; van Asselt, M. More evolution than revolution: transition management in public policy. Foresight 2001, 3, 15-31. [CrossRef]

19. Evans, J.; Karvonen, A. Living laboratories for sustainability: exploring the politics and epistemology of urban transition. In Cities and Low Carbon Transitions; Karvonen, A., Evans, J., Bulkeley, H., Castán Broto, V., Hodson, M., Marvin, S., Eds.; Routledge: London, UK, 2011; pp. 126-141.

20. Korsnes, M.; Berker, T.; Woods, R. Domestication, acceptance and zero emission ambitions: Insights from a mixed method, experimental research design in a Norwegian Living Lab. Energy Res. Soc. Sci. 2018, 39, 226-233. [CrossRef]

21. Grubler, A.; Wilson, C.; Bento, N.; Boza-Kiss, B.; Krey, V.; McCollum, D.L.; Rao, N.D.; Riahi, K.; Rogelj, J.; De Stercke, S.; et al. A low energy demand scenario for meeting the 1.5 textdegreeC target and sustainable development goals without negative emission technologies. Nat. Energy 2018, 3, 515-527. [CrossRef] 
22. Dubois, G.; Sovacool, B.; Aall, C.; Nilsson, M.; Barbier, C.; Herrmann, A.; Bruyère, S.; Andersson, C.; Skold, B.; Nadaud, F. It starts at home? Climate policies targeting household consumption and behavioral decisions are key to low-carbon futures. Energy Res. Soc. Sci. 2019, 52, 144-158. [CrossRef]

23. Sovacool, B.K. What are we doing here? Analyzing fifteen years of energy scholarship and proposing a social science research agenda. Energy Res. Soc. Sci. 2014, 1, 1-29. [CrossRef]

24. Lutzenhiser, L.; Gossard, M.H. Lifestyle, Status and Energy Consumption. In ACEEE Summer Study on Energy Efficiency in Buildings; American Council for an Energy Efficient Economy: Washington, DC, USA, 2000.

25. Allen, R.C. Energy Transitions in History: The Shift to Coal. RCC Perspect. 2013, 2, 11-16.

26. Stephenson, J.; Barton, B.; Carrington, G.; Gnoth, D.; Lawson, R.; Thorsnes, P. Energy cultures: A framework for understanding energy behaviours. Energy Policy 2010, 38, 6120-6129. [CrossRef]

27. Lettmayer, G.; Schwarzinger, S.; Koksvik, G.; Skjølsvold, T.M.; Velte, D.; Dimitrova, E.; Tasheva-Petrova, M.; Burov, A.; Mutafchiiska, I.; Biresselioglu, M.E.; et al. The impact of "Energy memories" on Energy Cultures and energy consumption patterns. Available online: https:/echoes-project.eu/sites/echoes.drupal.pulsartecnalia.com/ files/D5.2.pdf (accessed on 31 October 2019).

28. Ester, P. Consumer Behavior and Energy Conservation; Springer: Berlin, Germany, 2012.

29. Notter, D.; Meyer, R.; Althaus, H.-J. The Western Lifestyle and Its Long Way to Sustainability. Environ. Sci. Tech. 2013, 47, 4014-4021. [CrossRef]

30. Bin, S.; Dowlatabadi, H. Consumer lifestyle approach to US energy use and the related $\mathrm{CO}_{2}$ emissions. Energy Policy 2005, 33, 197-208. [CrossRef]

31. Kwac, J.; Flora, J.; Rajagopal, R. Lifestyle Segmentation Based on Energy Consumption Data. IEEE Transact. Smart Grid 2018, 9, 2409-2418. [CrossRef]

32. Axsen, J.; Cairns, J.; Dusyk, N.; Goldberg, S. What drives the Pioneers? Applying lifestyle theory to early electric vehicle buyers in Canada. Energy Res. Soc. Sci. 2018, 44, 17-30. [CrossRef]

33. Meyer, T. Das Konzept der Lebensstile in der Sozialstrukturforschung-eine kritische Bilanz. Soz. Welt 2001, 52, 255-271.

34. Weber, C.; Perrels, A. Modelling lifestyle effects on energy demand and related emissions. Energy Policy 2000, 28, 549-566. [CrossRef]

35. Sanquist, T.F.; Orr, H.; Shui, B.; Bittner, A.C. Lifestyle factors in U.S. residential electricity consumption. Energy Policy 2012, 42, 354-364. [CrossRef]

36. Howell, R.A. It's not (just) 'the environment, stupid!' Values, motivations, and routes to engagement of people adopting lower-carbon lifestyles. Global Environ. Change 2013, 23, 281-290. [CrossRef]

37. Schanes, K.; Giljum, S.; Hertwich, E. Low carbon lifestyles: A framework to structure consumption strategies and options to reduce carbon footprints. J. Clean. Prod. 2016, 139, 1033-1043. [CrossRef]

38. Samadi, S.; Gröne, M.-C.; Schneidewind, U.; Luhmann, H.-J.; Venjakob, J.; Best, B. Sufficiency in energy scenario studies: Taking the potential benefits of lifestyle changes into account. Technol. Forecast. Soc. Change 2017, 124, 126-134. [CrossRef]

39. Abrahamse, W.; Steg, L. How do socio-demographic and psychological factors relate to households' direct and indirect energy use and savings? J. Econ. Psychol. 2009, 30, 711-720. [CrossRef]

40. Newton, P.; Meyer, D. Exploring the Attitudes-Action Gap in Household Resource Consumption: Does ‘Environmental Lifestyle' Segmentation Align with Consumer Behaviour? Sustainability 2013, 5, 1211-1233. [CrossRef]

41. Moser, S.; Kleinhückelkotten, S. Good Intents, but Low Impacts: Diverging Importance of Motivational and Socioeconomic Determinants Explaining Pro-Environmental Behavior, Energy Use, and Carbon Footprint. Environ. Behav. 2017, 50, 626-656. [CrossRef]

42. Arnold, O.; Kibbe, A.; Hartig, T.; Kaiser, F.G. Capturing the Environmental Impact of Individual Lifestyles: Evidence of the Criterion Validity of the General Ecological Behavior Scale. Environ. Behav. 2018, 50, 350-372. [CrossRef]

43. Schwarzinger, S.; Bird, D.N.; Hadler, M. The 'Paris Lifestyle'-Bridging the Gap Between Science and Communication by Analysing and Quantifying the Role of Target Groups for Climate Change Mitigation and Adaptation: An Interdisciplinary Approach. In Addressing the Challenges in Communicating Climate Change Across Various Audiences; Leal Filho, W., Lackner, B., McGhie, H., Eds.; Springer: Berlin, Germany, 2018; pp. 375-397. 
44. Bohunovsky, L.; Grünberger, S.; Frühmann, J.; Hinterberger, F. Energieverbrauchsstile Datenbank zum Energieverbrauch österreichischer Haushalte: Erstellung und empirische Überprüfung. Endbericht 2011, 1, $1-53$.

45. Hierzinger, R.; Herry, M.; Seisser, O.; Steinacher, I.; Wolf-Eberl, S. Energy Styles. Klimagerechtes Leben der Zukunft - Energy Styles als Ansatzpunkt für effiziente Policy Interventions. Endbericht zum Projekt Energy Styles. Klima- und Energiefonds 2011, 1, 1-122.

46. Schulze, G. Die Erlebnisgesellschaft. Kultursoziologie der Gegenwart; Campus Verlag: Frankfurt am Main, Germany, 2005.

47. Prose, F.; Wortmann, K. Energiesparen: Verbraucheranalyse und Marktsegmentierung der Kieler Haushalte. Band 1, Die sieben Kieler Haushaltstypen-Werte, Lebensstile und Konsumentenverhalten; Projekt Klimaschutz; Institut für Psychologie, Universität Kiel: Kiel, Germany, 1991.

48. Degenhardt, L. Pioniere Nachhaltiger Lebensstile Analyse einer positiven Extremgruppe mit bereichsübergreifender Kongruenz zwischen hohem nachhaltigen Problembewusstsein und ausgeprägtem Nnachhaltigen Handeln; Kassel University Press: Kassel, Germany, 2007.

49. Binder, M.; Blankenberg, A.-K. Green lifestyles and subjective well-being: More about self-image than actual behavior? J. Econ. Behav. Organ. 2017, 137, 304-323. [CrossRef]

50. Kennedy, E.H.; Krahn, H.; Krogman, N.T. Are we counting what counts? A closer look at environmental concern, pro-environmental behaviour, and carbon footprint. Local Environ. 2015, 20, 220-236. [CrossRef]

51. Csutora, M. One More Awareness Gap? The Behaviour-Impact Gap Problem. J. Consum. Pol. 2012, 35, 145-163. [CrossRef]

52. Lutzenhiser, L.; Hackett, B. Social Stratification and Environmental Degradation: Understanding Household $\mathrm{CO}_{2}$ Production. Soc. Probl. 1993, 40, 50-73. [CrossRef]

53. Baiocchi, G.; Minx, J.; Hubacek, K. The Impact of Social Factors and Consumer Behavior on Carbon Dioxide Emissions in the United Kingdom. J. Ind. Ecol. 2010, 14, 50-72. [CrossRef]

54. Druckman, A.; Jackson, T. The carbon footprint of UK households 1990-2004: A socio-economically disaggregated, quasi-multi-regional input-output model. Ecol. Econ. 2009, 68, 2066-2077. [CrossRef]

55. Marquart-Pyatt, S.T. Public Opinion about the Environment: Testing Measurement Equivalence across Countries. Int. J. Sociol. 2015, 45, 309-326. [CrossRef]

56. Xiao, C.; Dunlap, R.E. Validating a Comprehensive Model of Environmental Concern Cross-Nationally: A U.S.-Canadian Comparison*. Soc. Sci. Q. 2007, 88, 471-493. [CrossRef]

57. Franzen, A.; Vogl, D. Two decades of measuring environmental attitudes: A comparative analysis of 33 countries. Global Environ. Change 2013, 23, 1001-1008. [CrossRef]

58. Otte, G. Construction and Test of an Integrative Lifestyle-Typology for Germany. Zeitschrift für Soziologie 2005, 6, 442-467.

59. Hermann, D. Bilanz der empirischen Lebensstilforschung. KZfSS Kölner Zeitschrift für Soziologie und Sozialpsychologie 2004, 56, 153-179. [CrossRef]

60. Lüdtke,H. Methodenprobleme der Lebensstilforschung. Probleme des Vergleichs empirischer Lebensstiltypologien und der Identifikation von Stilpionieren. In Lebensstil zwischen Sozialstrukturanalyse und Kulturwissenschaft; Schwenk, O.G., Ed.; VS Verlag für Sozialwissenschaften: Wiesbaden, Germany, 1996; pp. 139-163.

61. Otte, G. Hat die Lebensstilforschung eine Zukunft? KZfSS Kölner Zeitschrift für Soziologie und Sozialpsychologie 2005, 57, 1-31. [CrossRef]

62. Seebauer, S.; Fleiß, J.; Schweighart, M. A Household Is Not a Person: Consistency of Pro-Environmental Behavior in Adult Couples and the Accuracy of Proxy-Reports. Environ. Behav. 2017, 49, 603-637. [CrossRef]

63. Finkbeiner, M.; Inaba, A.; Tan, R.; Christiansen, K.; Klüppel, H.-J. The New International Standards for Life Cycle Assessment: ISO 14040 and ISO 14044. Int. J. LCA. 2006, 11, 80-85. [CrossRef]

64. Pandey, D.; Agrawal, M.; Pandey, J.S. Carbon footprint: current methods of estimation. Environ. Monit. Assess. 2011, 178, 135-160. [CrossRef]

65. Bird, D.N.; Schwarzinger, S.; Kortschak, D.; Strohmaier, M.; Lettmayer, G. Report: A Detailed Methodology for the Calculation of Cumulative Energy Demand per Survey Respondent. Available online: https://echoes-project.eu/sites/echoes.drupal.pulsartecnalia.com/files/documents/ECHOES-D5.1_ Energy_evaluation_methodology_191015_final.pdf (accessed on 31 October 2019). 
66. Bacher, J.; Wenzig, K.; Vogler, M. SPSS TwoStep Cluster-A First Evaluation, 2nd, corr. ed.; Arbeits-und Diskussionspapiere; Universität Erlangen-Nürnberg, Sozialwissenschaftliches Institut, Lehrstuhl für Soziologie: Erlangen, Germany, 2004; p. 23.

67. Kuha, J. AIC and BIC. Socio. Meth. Res. 2004, 33, 188-229. [CrossRef]

68. Schwarzinger, S.; Bird, D.N.; Lettmayer, G.; Henriksen, I.M.; Skjølsvold, T.M.; Olaeta, X.U.; Alvarez, L.P.; Velte, D.; Iturriza, I.J.; Biresselioglu, M.E.; et al. Comparative Assessment of European Energy Lifestyles. Available online: https://echoes-project.eu/sites/echoes.drupal.pulsartecnalia.com/files/D5.1.pdf (accessed on 31 October 2019).

69. Haufe, N.; Dangschat, J.S. Energiekonsum-sozial differenziert betrachtet. In Energie und soziale Ungleichheit: Zur gesellschaftlichen Dimension der Energiewende in Deutschland und Europa; Großmann, K., Schaffrin, A., Smigiel, C., Eds.; Springer: Berlin, Germany, 2017; pp. 635-662.

70. Greening, L.A.; Greene, D.L.; Difiglio, C. Energy efficiency and consumption-The rebound effect-A survey. Energy Policy 2000, 28, 389-401. [CrossRef]

71. Afionis, S.; Sakai, M.; Scott, K.; Barrett, J.; Gouldson, A. Consumption-based carbon accounting: Does it have a future? Wiley Interdiscip. Rev. Clim. Chang. 2017, 8. [CrossRef]

72. Davis, S.J.; Caldeira, K. Consumption-based accounting of $\mathrm{CO}_{2}$ emissions. Proc. Natl. Acad. Sci. USA 2010, 107, 5687-5692. [CrossRef] [PubMed]

(C) 2019 by the authors. Licensee MDPI, Basel, Switzerland. This article is an open access article distributed under the terms and conditions of the Creative Commons Attribution (CC BY) license (http://creativecommons.org/licenses/by/4.0/). 